\title{
Antlers Are Shaped as Elements of Concave Surfaces that Reflect and Concentrate Incoming Sounds
}

\section{Michelangelo Rossetto}

New York, USA

Correspondence to: Michelangelo Rossetto, marossetto@libero.it

Keywords: Moose, Antlers, Mating, Acoustics

Received: October 11, $2021 \quad$ Accepted: November 23, $2021 \quad$ Published: November 26, 2021

Copyright $\odot 2021$ by author(s) and Scientific Research Publishing Inc.

This work is licensed under the Creative Commons Attribution International License (CC BY 4.0).

http://creativecommons.org/licenses/by/4.0/

(c) (i) Open Access

\section{ABSTRACT}

In 1917 D'Arcy Thompson observed that the pair of antlers of a red deer, a sambur or a wapiti Make up between them a single surface that is more or less spherical or occasionally an ellipsoidal surface. The palmated antlers of the moose are explored to provide an example of how antlers can be instrumental in lowering the threshold sensitivity of hearing.

\section{INTRODUCTION}

The moose [Figure 1] lives a uniquely individual lifestyle that is not often found in the animal kingdom.

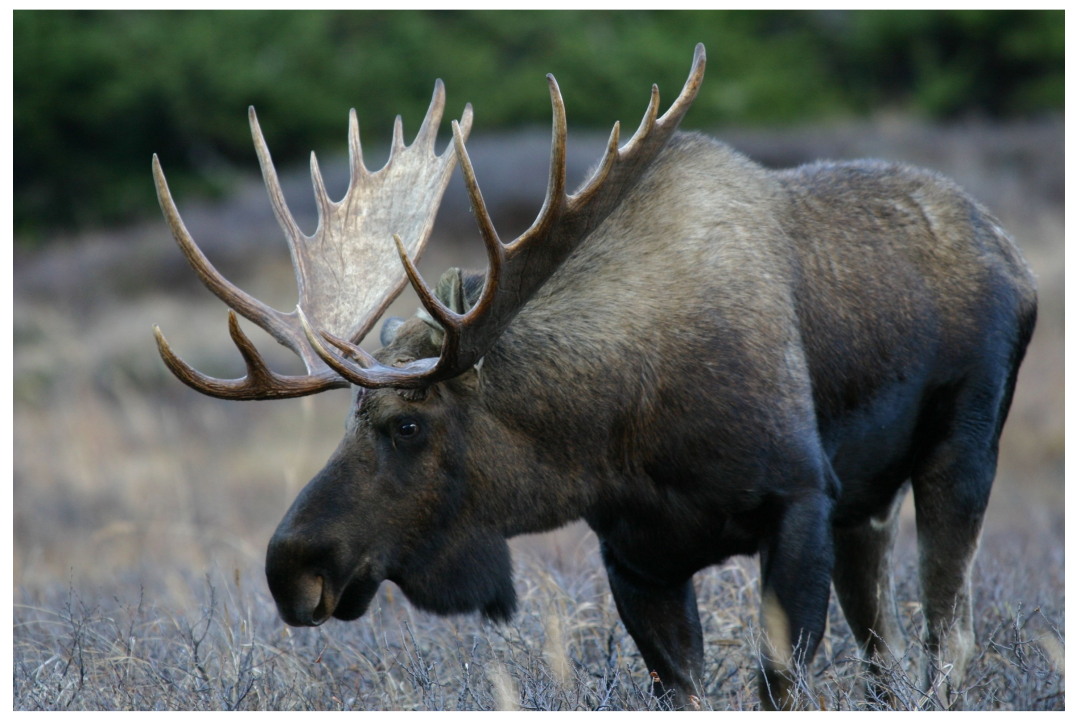

Figure 1. Moose with fully developed antlers.

https://en.wikipedia.org/wiki/Moose. 
The male moose has an almost completely solitary lifestyle. He lives in a vast wild environment that is rich with pasturage but devoid of any interaction with other moose. It is only around mating behavior that the male will briefly interact with other males while competing for a female. He then only briefly interacts with a female during the mating act [1].

This paper will argue that the majestic antlers of the moose have been physically shaped by the evolutionary necessity to optimize both acoustic sensitivity and acoustic direction-finding. The reproductive success of the moose depends on refining his acoustic direction-finding ability. Hooking up for mating is achieved through an interchange of long-distance acoustic mating calls. The challenge for the male moose is to find and connect with a female moose in the vast environment. It is the contention of this essay that the bowl-shaped antlers of the moose are being used to focus and concentrate sounds that are important during mating interactions.

\section{THEORY}

In order to understand how these elaborate appendages (which at first sight seem to be burdensome to the animal) can be of utility, it is necessary to consider some of the characteristics of a focusing-dish similar to the mirror of a reflecting telescope or the reflective dish of a radar antenna.

In the telescope, each small area of the mirror reflects light (which enters parallel to the mirror axis) toward the focal point. Each of these arbitrarily chosen small areas can be considered to operate as independent reflectors aimed to reflect onto the focal point. At the focal point, all these independent reflections will summate to express the amplification factor of the mirror.

If some parts of the mirror are removed, their contribution will be removed. However, those that remain will continue to contribute to the concentrating-action of the mirror. The intensity of the signal is reduced by the same amount as the mirror area has been reduced. If, for example, the mirror area is reduced by removing a wedge of one quarter the size of the mirror, the intensity at the focus will be reduced by one quarter. However, as long as the diameter and curvature of the reflector are constant, the concentrating-power of the remaining three quarters will remain the same.

In order to relate this physical telescope mirror example to the biological reality of how antlers in the moose and its relatives' function, consider the following Gedanken Experiment. Divide our hypothetical spherical telescope mirror in half with a vertical line. On one side draw an image of an antler and remove any part of the mirror that is "not antler". Then, on the other side of the line do the same, but as a "mirror image" of the first side. The parts of the mirror that remain (the image of the antlers cut out of the reflecting dish) will still function as a focusing reflector. Even though the intensity is only a fraction of that possible with the complete reflector, the summated reflection at the focus will be larger than the unmodified incoming wave. Additionally, it will be direction-sensitive.

The above example, which describes how light-reflecting mirrors work, was chosen because we are familiar with optical mirrors but not at all familiar with acoustical mirrors. Acoustical mirrors are viable analogs of optical mirrors if they are dimensioned large enough to contain one or more wavelengths of the acoustic signal. In older moose, the area between the tines begins to fill in, increasing the reflecting area and therefore the intensity of the reflection.

\section{HISTORY}

In order to relate these geometric concepts to the real-life situations of a moose, we turn to the observation that DiArce Thompson made in consideration of moose antlers in his 1916 book "On Growth and Form".

"The surface to which the branches of the antler tend to be confined is a more or less spheroidal, or occasionally an ellipsoidal one; and furthermore, when we inspect any well-developed pair of antlers, such as those of a red deer, a sambur or a wapiti, we have no difficulty in seeing that the two antlers make up between them a single surface. To put the case in another way, a pair of antlers (apart from occasional slight irregularities) tends to constitute a figure such that we could conceive an elastic sheet stretched over 
or around the entire system, and to form one continuous and even surface; and not only would the surface curvature be on the whole smooth and even, but the boundary of the surface would also tend to be an even curve that is to say the tips of all the tines would approximately have their locus in a continuous curve" [2].

Do these considerations and observations mean that the huge antlers carried by moose are being used to improve the animals' acoustic sensitivity?

In 2008 Bubenik, G. and Bubenik P. performed an acoustic experiment to test this concept on a pair of trophy moose antlers. They then wrote a pertinently titled paper: "Palmated antlers of moose may serve as a parabolic reflector of sounds". The concept, expressed by the title, was tested by a movable pseudo-ear with a microphone. When the frontal position of the ear toward the speaker was taken as $100 \%$, the backward position achieved a relative sound pressure of only 79\%, while the sideways position toward the antler palm had a relative pressure of $119 \%$. This measured data strongly supports the Bubeniks theory (which I also share) that the enormous antlers of the moose, which can be up to two meters wide, are an acoustic apparatus [3].

DiArce Thompson also called out the Sambar deer as an example of antlers as ribs of a spheroidal focusing surface.

The tines of the Sambar deer antler in Figure 2 are like the ribs of an imaginary spherical surface that becomes obvious to the eye once it is prompted. The analysis of a partial spherical mirror, presented above, leads to an understanding that ribs of a spherical surface can act as a spherical reflector.

\section{MOOSE ACOUSTICS}

To better understand how the behavior of the moose is dependent on acoustics, it is helpful to follow the behavior for one annual cycle of a fully mature male adult. We start with the shedding of the antlers at the start of the year in January.

The moose is now free of the cumbersome antlers for several months. However, with the coming of spring, in March or April, a new set of antlers begins to grow. From their first appearance until their full maturity, they are covered with a soft layer of "velvet". This velvet covering contains nerves and, more importantly, blood vessels that nurture the antlers as they grow. This growth proceeds at an unusually rapid pace. The enormous antlers of the moose (which are made of bone and can have a spread of two

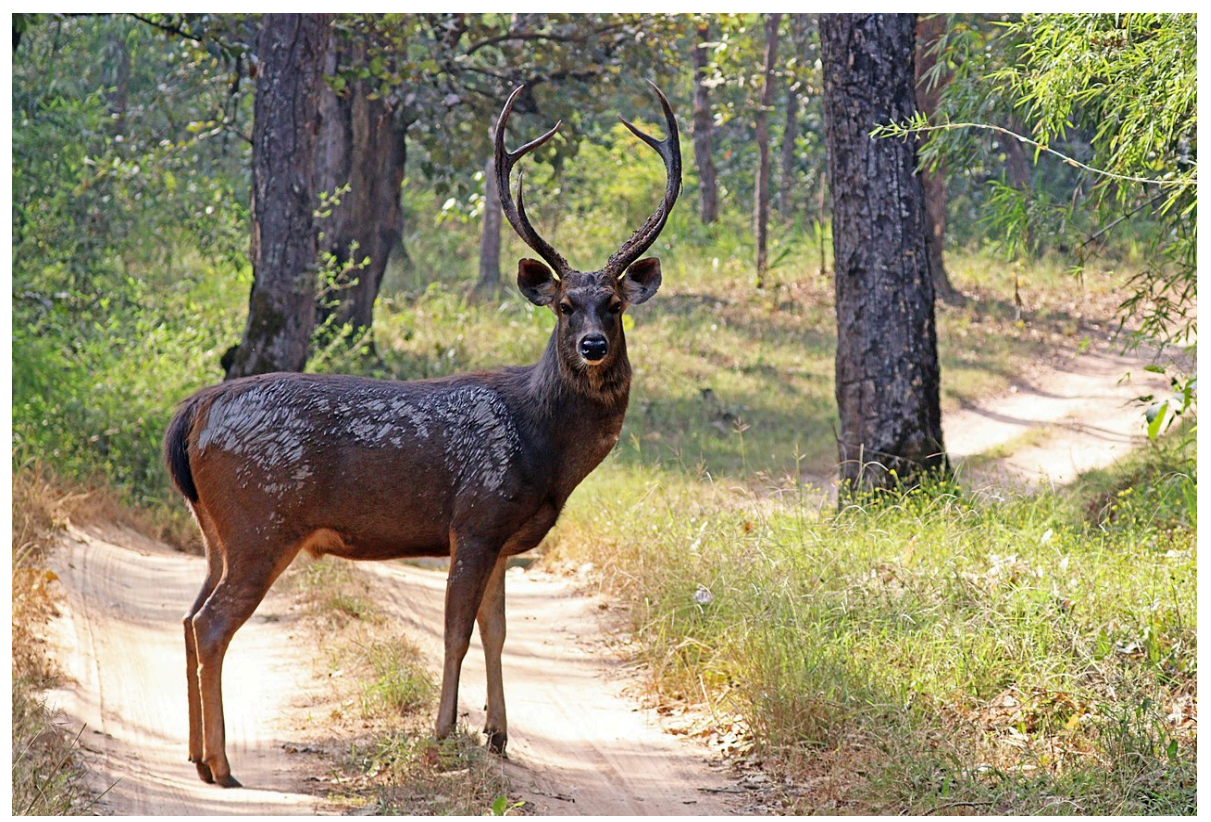

Figure 2. Sambar deer whose antlers define a surface which we argue is an acoustic reflector. https://en.wikipedia.org/wiki/Sambar_deer. 
meters) will be fully developed by the end of August. At this time, the velvet covering begins to die and is shed, often with the help of the moose as he scrapes his antlers against bushes or small trees. When the antlers are covered with the soft velvet that nurtures their growth they will not be good reflectors of sound. It is only when the bone surface is fully exposed that the antlers will start becoming efficient sound-reflectors. Then, the moose will begin to use them in the service of finding and impregnating a mate.

The female moose spends only a short time in rut (the period of sexual receptivity). This period of receptivity typically falls between mid-September and mid-October. It is in this short window of time that the male moose must abandon his solitary existence to find a female to mate with. The moose habitat encompasses very large areas. Since acoustics are the way the mating hook-up is achieved, a very efficient acoustic channel must be utilized.

The acoustic behavior of the moose follows a fixed pattern. First, the male moose lets out a series of loud, low-frequency bellows. This low-frequency sound can travel a long-distance and announces his presence to the female. If the female is interested she will respond with a unique call that is only used in the rut. Then the male, using the directional-focused antlers carried on its head, zeros in on the female's location and moves towards her until they meet.

This locating behavior is exploited by moose hunters. They wait till they hear the male "bellow" and then mimic the female's call. The male moose, drawn to the sound of a receptive female, then becomes a target for the hunter [4]. If the moose avoids the hunters he will spend hours to days convincing a female to mate. He will then return to his solitary existence, leaving the female to gestate and birth alone.

The male moose keeps his antlers from the time of mating in September or October until January, when they will be jettisoned. It is generally argued that the antlers are no longer needed after mating and that the moose would benefit from eliminating them immediately. However, some data suggest that the antlers may be useful in avoiding predation in the early winter months seeing as a disproportionate number of antlerless moose suffer predation by wolves [5]. With antlers, the moose has enhanced hearing with directional sensitivity. He can track (acoustically) the presence of predators. Then, he can take appropriate evasive actions. Also by using antlers as a defensive weapon, the lhuge antlers can discourage predation.

\section{CONCLUSIONS}

By understanding how the tines of the antler are the reflective ribs of a spherical acoustic reflector, we are able to see how structure evolves to follow function in the acoustic sense of the moose and its relatives. The development of a spherical acoustic reflector is a response to the need to maximize the threshold detection of the distant female mating call. He who hears the rut vocalization first is the first to mate. Threshold acoustic sensitivity underlies the evolutionary gradient that works toward enhancing survivability of the moose and its relatives.

It has long been appreciated that the Moose antlers were important to, and synchronized to, the reproductive cycle. They were thought to be weapons supporting mating success by fending off rivals. Instead we find that fighting is secondary to finding.

The moose understandably uses his directionally-sensitive antlers to locate the call of his mate. However, it is not so obvious that the antlers also work in the other direction. Simple (linear) acoustic devices are bi-directional. We should, therefore, expect the moose antler to reflectively enhance the outgoing mating bellows.

Keeping in mind the spherical surface defined by the samber's antlers, we see how fitting (to the analysis of antlers) is Galileo's Aphorism "The Book of Nature is Written in characters of Geometry" [6].

\section{ACKNOWLEDGEMENTS}

The editorial assistance of Marina Chiaramonte is much appreciated.

\section{CONFLICTS OF INTEREST}

The author declares no conflicts of interest regarding the publication of this paper. 


\section{REFERENCES}

1. Silliker, B. (1998) Moose: Giants of the Northern Forest. Firefly Books, Buffalo.

2. Thompson, D.W. (1917) On Growth and Form. The University Press, Cambridge. https://doi.org/10.5962/bhl.title.11332

3. Bubenik, G.A. and Bubenik, P.G. (2008) Palmated Antlers of Moose May Serve as a Parabolic Reflector of Sounds. European Journal of Wildlife Research, 54, 533-535. https://doi.org/10.1007/s10344-007-0165-4

4. Kelso, D. (2014) Moose Hunting. Skyhorse Publishing, New York.

5. Metz, M.C., Emlen, D.J., Stahler, D.R., et al. (2018) Predation Shapes the Evolutionary Traits of Cervid Weapons. Nature Ecology \& Evolution, 2, 1619-1625. https://doi.org/10.1038/s41559-018-0657-5

6. Galilei, G. (2012) Galileo, Selected Writings. Translated by: Shea, W. and Davie, M., Oxford University Press, Oxford. 